\title{
Game Analysis on the Effectiveness of Signing Anti- leakage Articles of Business Contract
}

\author{
Xiuli Tan \\ School of Business \\ Yantai Nanshan University \\ Yantai, Shandong, China 265713
}

\author{
Jinhua Li \\ School of Business \\ Yantai Nanshan University \\ Yantai, Shandong, China 265713
}

\author{
Ping Wang \\ School of Business \\ Yantai Nanshan University \\ Yantai, Shandong, China 265713
}

\begin{abstract}
The paper starts from the microcosmic angle of signature of business contract, analyzes the strategy adopted in signature of contract to prevent leakage of business secret with the basic principle of game theory. It puts forward 3 strategies including bilateral effectiveness, unilateral effectiveness and bilateral strategy of the signature of contract, and conducts empirical analysis to these. The research conclusion has certain application value for signature of anti-leakage business contract, and reference significance for various business subjects and law enforcement agencies.
\end{abstract}

Keywords-contract item; business secret; game analysis; effectiveness

\section{INTRODUCTION}

At present, the researches of scholars at home and abroad on protection of business trade mainly involve 3 aspects: firstly it's about research on protection of business trade. Xu Rui thinks that our country should clarify a series of concepts such as acquiring business secret by improper means, stipulate protective means like prohibition and temporary measure, at the same time, it shall prevent abuse of civil rights; [1] $\mathrm{Hu}$ Liangrong points out to refer to experience of foreign legislation, and apply both punitive and compensating compensation system to the compensation of infringement of trade secret; [2] Fan Xiaobo takes case analysis method and points that the court decides the punishment fits the crime according to the loss calculated by the appraisal agency, and focuses on analyzing the appraisal procedure, existing problem and evaluation rule of the appraisal agency;[3] See Michael J. Nutter conducts defining study to the judgement standard of acquiring trade secret by improper means. [4] Secondly it's about the comparative study of protecting trade secret. Shen Qiang researches Trips agreement and the system of civil remedies for trade secrets, and puts forward new opinions on confirmation of trade secret right, burden of proof and distribution; [5] Sun Yiwu points out that our country should refer to the experience of EU launching "Instruction on preventing acquiring, using and publishing proprietary technology and business information", revise and optimize the law system of protecting trade secret; [6] Zhou Lin concludes preventive protection mode into blending mode of property and contractual protection and single contractual preventive protection mode based on comparing and analyzing the preventive protection of trade secret of various countries, and discusses the applicability of our country's contract; [7] Robert C. Van Arnam points out in his research that Trips confirms the international standard of protecting trade secret, and admits the independent status of the trade secret right. [8] Thirdly it's about the research on protection of trade secret in contractual labor relationship. Susan Street Whaley thinks that the negative influence of the non-competition agreement is to limit the freedom of employees' job selection and mobility, and severely weaken the competitiveness of employees; [9] Krishna L. Carey points out that non-competition agreement hinders technical spread, weakens the overall technical research and development ability of the region, and influences the improvement of the overall technical level of the region; [10].

Although many scholars develop fairly deep research on the protection of trade secret from macroscopic perspective or overall aspect, most scholars have not developed the research on effectiveness of preventing business secret leakage of the detailed business contract clauses. The paper starts from microcosmic perspective and sets up game mode of mixed strategies of signing parties of the contract based on above research basic, and researches the formulation strategy of antileakage items in business contract based on analyzing the protective strategies of trade secret of the signing parties of the contract. The research method is innovative in some degree.

\section{RELEVANT CONCEPT AND MODEL ASSUMPTION}

Trade secret refers to technical information and business information which is unknown to the public, can bring economic interest to the oblige, has practicability and protected by the oblige. The confidential information generally refers to information with value which is unknown to the public or 
competitor, whose range does not only limit to trade secret, but also includes other information, but the trade secret is the most important protecting object to it. The confidential information in this paper only refers to trade secret. According to the legal relation between the involved parties, the agreement of trade secret is divided into confidentiality agreement of the nature of labor contract and confidentiality agreement of nature of general civil and commercial contract.

Suppose the Party A has a trade secret in a business contract (hereinafter referred to as contract), during the signature of the contract of the two parties, the party A has to show this secret to the party $\mathrm{B}$, if the two parties reach an agreement and sign the contract, the two parties shall take effective measures to protect this trade secret. If the two parties fail to reach an agreement, the party $\mathrm{B}$ shall keep the trade secret for the party A; otherwise the party A has the right to charge the Party B with damaging its legal interest and obtain economic compensation.

Now suppose the two parties fail to reach an agreement or they reach an agreement but the party B violates the contract, the two parties launch a game around the agreement of keeping trade secret. Stipulate g represents the economic loss suffered by Party A due to the party B's violation; b represents the litigation cost of the party A apart from the court cost for charging party B; c represents the profit gained by the party B from leaking the Party A's trade secret; a represents the economic compensation undertaken by the Party A if it loses the lawsuit; $m_{1}$ represents the party A's expense in litigation; $m_{2}$ represents the party B's cost of response; y represents the ratio of party $B$ leaking party A's trade secret, $x$ represents the ratio of the party $\mathrm{A}$ charging the party $\mathrm{B}$.

\section{GAME ANALYSIS OF THE SIGNING PARTIES OF THE CONTRACT}

\section{A. Game Analysis}

The payoff matrix of the game between the two parties is as follow ("Table I"):

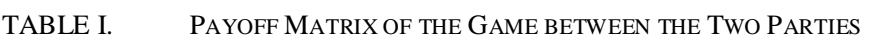

\begin{tabular}{llll}
\hline $\begin{array}{l}\text { Strategy selection } \\
\text { (ratio) }\end{array}$ & $\begin{array}{c}\text { Party B leaking the } \\
\text { secret }(\mathbf{y})\end{array}$ & $\begin{array}{c}\text { Party B not leaking the } \\
\text { secret }(1-y)\end{array}$ \\
\hline $\begin{array}{l}\text { Party A } \\
\text { charging (x) }\end{array}$ & not & $\left(a-b, c-d-a-m_{1}\right)$ & $\left(-b-e-m_{1}-m_{2},-d+e\right)$ \\
$\begin{array}{l}\text { Party A } \\
\text { charging(1-x) }\end{array}$ & not & $(g, c)$ & $(0,0)$ \\
\hline
\end{tabular}

From

Table

$E_{J}=\mathrm{x}\left[y(a-b)+(1-y)\left(-b-e-m_{1}-m_{2}\right)\right]+(1-x) y g$

it can be calculated that the maximal expected profit of the party $\mathrm{A}$ is:

$$
\frac{\partial E_{J}}{\partial \mathrm{x}}=y\left(a+e+g+m_{1}+m_{2}\right)-\left(b+e+m_{1}+m_{2}\right)
$$

Make $\frac{b+e+m_{1}+m_{2}}{a+e+g+m_{1}+m_{2}}=\lambda$, obviously $b \leq a+g$, so $0<\lambda \leq 1$. When $y<\lambda, \frac{\partial E_{J}}{\partial x}<0$, at this time, the party A will gain maximal expected profit if it does not charge, namely $x=0$; when $y=\lambda, \frac{\partial E_{J}}{\partial x}=0$, at this time, no matter how the party A chooses, it will gain the maximal expected profit, namely $x$ can be any value in $[0,1]$; when $y>\lambda, \frac{\partial E_{J}}{\partial x}>0$, at this time, the party A will gain maximal expected profit if it chooses to charge, namely $x=1$. Thus it can be acquired that the Party A's best reaction function is:

$$
x(y)=\left\{\begin{array}{cc}
0 & y<\lambda \\
{[0,1]} & y=\lambda \\
1 & y>\lambda
\end{array}\right.
$$

The maximal expected profit of the party B:

$$
\begin{aligned}
& E_{Y}=y\left[x\left(c-d-a-m_{1}\right)+(1-\mathrm{x}) c\right]+(1-y)[x(-d+e)] \\
& \frac{\partial E_{Y}}{\partial y}=x\left(-a-m_{1}-e\right)+c
\end{aligned}
$$

Make $\frac{c}{a+m_{1}+e}=\mu$. In this condition, if $x=\mu$, then $\forall y \in[0,1] \quad, \quad$ so $\quad \forall y \in[0,1] \quad$; $\quad$ if $x<\mu \quad$ Then $\quad \frac{\partial E_{Y}}{\partial y}>0 \quad$, So $久 y=1$ $x>\mu$, Then $\frac{\partial E_{Y}}{\partial y}<0, \quad$ So $L y=0$ acquired that the Party B's best reaction function is:

$$
y(x)=\left\{\begin{array}{cl}
1 & x<\mu \\
{[0,1]} & x=\mu \\
0 & x>\mu
\end{array}\right.
$$

It can be calculated from formula (1) and (2) that the Nash equilibrium of the mixed strategies of game between the two parties is:

$$
\left(x^{*}, y^{*}\right)=(\mu, \lambda)=\left(\frac{c}{a+m_{1}+e}, \frac{b+e+m_{1}+m_{2}}{a+e+g+m_{1}+m_{2}}\right)
$$


It's not difficult to see from the Nash equilibrium above mixed strategy:

When $c<a+m_{1}+e$, the smaller $c$ is, the bigger $a, m_{1}$ and $e$ are, the smaller ratio of Party A charging Party $\mathrm{B}$, otherwise bigger; especially when $c=0$, the party A would definitely not charge; however, when $c=a+m_{1}+e$, no matter how $c, a, m_{1}$ and $e$ change, the Party A would definitely charge.

When $b<a+g$, the smaller $b, e, m_{1}$ and $m_{2}$ are, or the bigger $a$ and $g$ are, the smaller ratio of party B leaking the trade secret of the party A, otherwise the bigger; especially when $b=e=m_{1}=m_{2}=0$, the party B would definitely not leak the secret; however, when $b=a+g$, no matter $b, e$, $m_{1}, m_{2}, a$ and $g$ change, the party B will leak the trade secret of the party A.

Thus the following conclusion can be drawn:

- $\quad c$ only effects the party A but has no restraint to party $\mathrm{B}$, and the smaller $C$ is, the less possible is party A to charge, especially when $c=0$, the party A would definitely not charge.

- $b, m_{2}$ and $g$ only effect party B and has no restraint to the party $\mathrm{A}$, and the smaller $b$ and $m_{2}$ are, or the bigger $g$ is, the less possible is party B to leak the trade secret of the party A.

- $a 、 m_{1} 、 e$ effect the both parties, and $a$ has restraint to the both parties, namely increasing $a$ is not only good for the party A not to leak the secret, but also good for the party A not to charge; however, $m_{1} 、 e$ are on the contrary, which have opposite effect on the two parties, increasing $m_{1} 、 e$ will reduce the ratio of party A's charging, thus during the formulation of business items, there will be negotiation.

\section{B. Formulation of Contract Items}

1) Bilateral effectiveness strategy: Strategy 1. Increase the value of $a$ as much as possible to reduce the possibility of party B's secret leakage and party A's charging.

It can be known from the conclusion 3 that the bigger $a$ is, the more the party A dare not leak the secret, and the party A will not charge. The strategy of signing the contract is, the party A increases the limit of $a$ via items of liquidated damages or compensation for damages to improve the effectiveness of the contract.

2) Unilateral effectiveness strategy: Strategy 2. Reduce the value of $C$ as much as possible, which can effectively decline the ratio of the Party A charging, but has no influence on the party B. The conclusion 1 manifests: the party A thinks that the larger profit of the party B leaking the party A's trade secret, the more possible is it to leak the secret, and the more possible is party A to charge the party $\mathrm{B}$; otherwise, the less possible is the party A to charge the party $\mathrm{B}$. To reduce $c$ as much as possible, the contract item can be set as: the party B had to get approved by the party $\mathrm{A}$ in written before disclosing the trade secret. Otherwise the profit gained by the party $\mathrm{B}$ by leaking secret belongs to the party A, thus the party B will give up the plan of leaking secret from the beginning of contract signature.

Strategy 3. Increase the value of $g$ as much as possible, which can effectively reduce the ratio of the party B's leaking secret and has no influence on the party A. The conclusion 2 manifests: the smaller $g$ is, the more possible is the party B to leak the secret; the bigger $g$ is, the more the party B worry about the party A's revenge and it won't leak the secret. Thus the contract can be set as: the party A increases the limit of $g$ via clauses of liquidated damages or compensation for damages to reduce the ratio of the party B's leaking secret.

Strategy 4. Reduce the value of $b$ as much as possible, which can effectively decline the ratio of the party B's leaking secret and has no influence on the party A. The conclusion 2 manifest that, the party $\mathrm{B}$ thinks that the higher the litigation cost of the party A apart from the court cost for charging party $\mathrm{B}$, the more the party $\mathrm{A}$ is afraid of lawing, and the more possible is the party B to leak the secret; otherwise, the less dare the party B leak the secret. Thus the contract clauses can be set as: part or all of $b$ is undertaken by the party B to effectively decline the ratio of the party B's leaking secret.

Strategy 5. Reduce the value of $m_{2}$ as much as possible, which can effectively decline the ratio of the party B' $s$ leaking secret and has no influence on the party A. The conclusion 2 manifest that, the higher the appearance fee of the party $\mathrm{B}$, the more possible is the party B to leak secret, and the party B thinks that not leaking secret bears the name of leaking secret in vain and will pay high cost, by contrast, leaking secret is more beneficial to it. Given this, the contract clause shall be set as: the party A falsely charges the Party B with leaking secret, and the appearance fee, attorney fee and travel and hotel expenses of the witness to appear in court shall be partly or wholly undertaken by the Party A (1\%-100\%). It's appointed that the bigger the value of $m_{2}$, the less possible is the party B to leak secret.

3) Bilateral strategic solution: Strategy 6. Confirm the value of $e$ based on negotiation, try to consider the interest of the two parties and make the both parties able to accept. The conclusion 3 manifest that, the larger the economic compensation paid by the party $\mathrm{B}$ if losing the lawsuit, the less possible is the party A to charge, and the more possible is the party B to leak secret; the smaller $e$ is, the more possible is the party A to charge, the less possible is the party B to leak secret. Thus the economic compensation paid by the party $\mathrm{B}$ for losing the lawsuit affects both the two parties, and the effect direction is opposite. Thus it can't take extreme value 
but shall consider the interest of the both parties. Thus, the contract clause can be set as: $e$ is decided based on the negotiation of the two parties or decided by the judge. Thus the value of $e$ is the result of bargain of the two parties, also influenced by the judge.

Strategy 7 . Confirm the value of $m_{1}$ based on negotiation, try to consider the interest of the two parties and make the both parties able to accept. The conclusion 3 manifests that, the higher the charging cost of the party $\mathrm{A}$, the less possible is the party A to charge, the more possible is the party A to leak the

secret; the smaller $m_{1}$ is, the more possible is the party $\mathrm{A}$ to charge, the less possible is the party B to leak the secret. The charging cost of the party A influences the both parties, and the effect direction is opposite, thus it can' t take extreme value but shall consider the interest of the both parties. Thus, the contract clause can be set as: the amount of charging cost is decided by the court. There will not be extreme value in the payment of charging cost. The two parties' negotiation or the court's discretion considers the interest of the two parties, and they can both accept.

\section{CASE ANALYSIS}

This is a true case: the accuser is company $\mathrm{M}$ (hereinafter referred to as the party $\mathrm{A}$ ), the joint defendants are factory $\mathrm{T}$ (hereinafter referred to as the party B) and company $\mathrm{X}$ (hereinafter referred to as the party $\mathrm{C}$ ). The three parties signed the 5 contracts of manufacture of the mechanical part of 9 BTL serial coating machine in 2011.3. The contract appointed that the party $\mathrm{B}$ was responsible for keeping secret for the drawing material delivered by the party $\mathrm{A}$; the party $\mathrm{A}$ shall appoint personnel to lead the assembly and check and accept before livery. The party A fulfills obligations to the party B according to the agreement. In 2012.8, the part A found that the Party B was producing 7 coating machines the same as BTL series for the party C and it allowed the party C's staff to watch the assembly of the machine on the site and put into service. The party A thought that the party B invaded its trade secret and failed to persuade it and brought the case to court. According to relevant law, the court judged that the accused Parties B and C shall stop the infringement act at once, offered an apology and shall not expand the range of knowing the trade secret, and the party B shall compensate 168500 yuan for the economic loss of the party $\mathrm{A}$, the party $\mathrm{C}$ shall compensate 326856.86 for the economic loss of the party A. The charging cost shall be undertaken by the parties $\mathrm{A}$ and $\mathrm{B}$.

The above case is a typical case of contract secret leakage. It is not difficult to find in the analysis that restraint provisions such as "bilateral effect" and "unilateral effect". If the following restraint provisions are clarified at the beginning when the confidentiality agreement is signed, the ratio of such case will decline.

- Add the following clauses with "bilateral effectiveness strategy": the party B does not perform the duty of confidentiality, and shall bear violation responsibility, pay $30 \%$ of the actual loss caused to the party $\mathrm{A}$ as liquidated damages. The compensation for loss is the actual economic loss caused to the Party A by the nonperformance of the Party $\mathrm{B}$, and the calculating method is: the sales volume of the party A's products declines due to the infringement act of the Party B, and the loss is the product of reducing amount multiplied by each product's profit; If it's hard to calculate the loss of the party A according to the above method, the loss compensation sum is the whole profit gained by the party B by violating the agreement, and the calculating method is as above.

- Add the following clauses with "bilateral effectiveness strategy": the party B does not perform the duty of confidentiality, the reasonable cost paid by the party A for inspection and calling to account of the party B, such as travel expense and inspection expense shall be included in the compensation sum for the loss, and the party B shall compensate $100 \%$. The party B does not perform the duty of confidentiality, the attorney fee, witness fee, preserving cost and technical evaluation cost shall be $100 \%$ undertaken by the party B.

Sign the above contract under the guidance of "bilateral effectiveness strategy" and "bilateral effectiveness strategy", awe the party B, which will not choose to violate the contract under rational decision, for violating the contract cannot reach the objective of signature, and loss out weights the gain.

\section{CONCLUSION}

There are 3704 legal instruments if you type in dispute on confidentiality agreement in http://wenshu.court.gov.cn/, the processing time of some cases last for years, and the sum involved in some cases reaches tens and millions of yuan, and it can seen that there are many of such cases and the influence is great. If the parties can clarify their right and obligation via anti-leakage contract beforehand and reduce such cases, it has important meaning for commercial subjects, court and procurator rate.

The paper starts conducts exploratory research of the effectiveness of the anti-leakage business contract in the microcosmic angle with the basic principle of game theory. It puts forward 3 types and 7 strategies of formulating antileakage contract. The bilateral effectiveness strategy has restraining force to the both parties; the unilateral effectiveness strategy has restraining force to only one party; the bilateral strategy has waxing and waning effect on the two parties.

Under certain conditions, the research conclusion points clear direction to the formulation of the anti-leakage clauses. But there is no experimental study, so the research result of the paper awaits further test in practical work, which is the work the author plans to do in the future.

\section{REFERENCES}

[1] Xu Rui. Protection and limit of trade secret [J]. Intellectual property, 2015,0(1): 82-85

[2] Hu Liangrong [1,2]. Discussion on the applicability of punitive damages of violating trade secret [J]. Intellectual property, 2015,0(11): 62-67.

[3] Fan Xiaobo. Research on confirmation of "major loss" of violating trade secret-focusing on loss evaluation [J]. Intellectual property, 2014, (7): 23-28. 
[4] See Michael J. Nutter."The Case for Adoption of A Uniform Trade Secrets Act in New York", [C] Albany Law Journal of Science\&Technology, 10 Alb. L. J. Sci.\&Tech. 1 (1999).P.21.

[5] Shen Qiang. Comparative study on TRIPS agreement and trade secret civil relief system [D]. Shanghai: East China University of Political Science and Law.2010.5.

[6] Sun Yiwu. Legislation of protection of trad secret of EU and its enlightenment [J]. German Studies, 2014,0 (3): 81-93.

[7] Zhou Lin. Comparative study on preventive protection of trade secret [D]. Dalian: Dalian Maritime University. 2012.6

[8] Robert C.Van Arnam.Economic Espionage in the United States and the European Union and the Need for Greater Trade Secret Protection[J]. N. C. J. Int'1 L. \&Com.Reg., 2001, (fall): 27-95.

[9] Susan Street Whaley.The Inevitable Disaster of Inevitable Disclosure, University of Cincinnati Law Review[J], Spring 1999, PP842 - 844.

[10] Krishna L.Carey.Beyond the Raxt 128 Paradign; Emerging Legal Alternatives to the Non-compete Agreement and Their Potential Effect on Developing High-technology Markets, Journal of Small and Emerging Business Law[J],Spring 2001, pp.137-138. 